\title{
Os talentos e a cultura: a trajetória de Anita Malfatti
}

\author{
Denise Rocha Belfort Arantes-Brero*
}

\section{Resumo}

Muito se tem pesquisado sobre os indivíduos dotados e talentosos, havendo, em diversos momentos históricos, preocupação com essa população. No Brasil, uma das primeiras vezes em que se falou disso foi na década de 30, por ocasião da fundação da Sociedade Pestalozzi. Apesar desse interesse crescente, na atualidade, existem poucas pesquisas que versam sobre o tema. Este trabalho visa entender como dotação e talento podem se manifestar e serem reconhecidos pela sociedade e cultura na qual a pessoa está inserida, com base na análise da biografia de Anita Malfatti (18891964), pintora expressionista, incompreendida em sua época, por ter introduzido uma forma de pintar que não era reconhecida como arte no Brasil. Neste estudo, será apresentada a teoria de Gagné, bem como o que se pretende nomear com os termos dotação e talento. O grande desafio de nossa sociedade é reconhecer as diferenças e valorizá-las, oferecendo a essas pessoas condições para expressão de suas habilidades, garantindo-lhes plena inserção na vida em sociedade para que se sintam produtivas e autorrealizadas. Precisamos lutar contra a "solidáo do fundista", para que o talentoso não esteja sempre adiante dos demais no aspecto intelectual, mas emocionalmente solitário e incompreendido.

Palavras-chave: Dotação; Talento; Superdotação.

* Doutoranda do Programa de Psicologia do Desenvolvimento e Aprendizagem da Universidade Estadual Paulista, Bauru, São Paulo, Brasil. 


\title{
Talents and culture: the paths of Anita Malfatti
}

\begin{abstract}
There are several studies about gifted and talented individuals and, in several historic moments, there has been concern with this population. One of the first occasions when this subject was discussed in Brazil was in the 1930's on occasion of the beginning of the Pestalozzi Society. In spite of the growing interest in the subject, there are currently few studies about this subject. This paper aims to understand how gift and talent may manifest and be recognized in the society and culture in which the person is inserted, based on the biography of Anita Malfatti (1889-1964), an expressionist painter, misunderstood in her time, for introducing a way of painting that was not recognized as art in Brazil. This study will present the theory by Gagné, as well as that that will be named by the terms gift and talent. The great challenge in our society is recognizing differences and valuing them, offering these people the means to express their skills, assuring that they are fully inserted in social life and thus feel productive and fulfilled. We must fight against the "solitude of the distance runner", so that those who are talented are not always ahead of the rest in the intellectual aspect, emotionally lonely and misunderstood.
\end{abstract}

Keywords: Endowment; Talent; Gifted.

\section{Introdução}

As pessoas talentosas despertam interesse e, nos últimos anos, houve um aumento nas publicaçôes sobre essa temática no Brasil, no entanto, é importante refletir sobre o que leva uma pessoa a ser efetivamente reconhecida como talentosa. Qual a importância da cultura e da sociedade em que vivemos para o reconhecimento dos talentos?

Esse questionamento se tornou mais presente a partir do contato com a biografia de Anita Malfatti, uma mulher revolucionária, que lutou contra o preconceito, pelo fato de ser mulher e por trazer uma nova arte, que náo era reconhecida como tal, na cultura na época.

Essa mulher talentosa sofreu com o preconceito e a não aceitaçáo do seu talento, por parte da sociedade. Isso influenciou também sua formaçáo acadêmica, pois o tio, que mantinha seus estudos, decidiu não mais fazê-lo ao perceber que suas produçôes eram diferentes das valorizadas na época. Sua pintura e seu estilo, totalmente novos no país, foram aperfeiçoados ao longo do tempo e de diversas idas ao exterior, para estudar.

Além disso, sua deficiência física não a impediu de manifestar seu talento, chamando atenção para a possibilidade de uma pessoa com deficiência também ser dotada e talentosa.

Este artigo objetiva analisar como a dotação e o talento podem se manifestar e como se dá o reconhecimento deles pela sociedade e pela cultura na qual a pessoa está 
inserida. Assim, é possível pensar como a escola pode atuar, abrindo possibilidades para que os alunos expressem seus potenciais e possam ser reconhecidos e orientados a desenvolver seus talentos.

\section{Revisão de literatura}

Em diversos momentos históricos, houve uma preocupação com as pessoas talentosas, Platão procurava jovens com inteligência elevada e educava-os com o objetivo de torná-los líderes de Estado (ALMEIDA; CAPELLINI, 2005).

No Brasil, uma das primeiras vezes em que se falou sobre o tema, foi na década de 30, por ocasião da fundação da Sociedade Pestalozzi, que preconizava em seus estatutos o atendimento à população escolar "situada no extremo superior da distribuição das capacidades humanas" (GUENTHER, 2008, p. 10).

Essa preocupação perdura até os dias de hoje, e, muitos autores, (LANDAU, 2002; DELOU, 2007; VIRGOLIM, 2007) ressaltam a importância do investimento nesses indivíduos, pois eles poderão desempenhar funçóes que alavancarão o desenvolvimento do país, modificando a sociedade onde vivem e essa "é a grande tarefa da Educação" (GUENTHER, 2003, p. 31).

Segundo a Organização Mundial da Saúde (OMS), 3\% a 5\% da população geral possui um potencial superior, em alguma área do desenvolvimento humano, em comparação com seus pares de idade.

Essas são pessoas iguais às outras, com peculiaridades próprias de sua idade e de sua fase de desenvolvimento, que são influenciadas pelas questôes ambientais e socioculturais nas quais estâo inseridas. Aliás, a valorização do potencial superior pela sociedade constitui-se no princípio básico do conceito de dotação e talento defendido por François Gagné e Zenita Guenther (GUENTHER, 2006a, p. 35).

Em relação à prevalência, há talentos em todas as raças, classes sociais e povos, captáveis por meio da produção diferenciada em um ou mais dos quatro domínios identificados por Gagné: inteligência e capacidade intelectual; criatividade e pensamento criador; domínio socioafetivo e domínio sensoriomotor (GUENTHER 2006a, p. 22), confirmando que a inteligência é democrática e derrubando o mito de que somente pessoas oriundas de camadas sociais privilegiadas seriam dotadas e talentosas por estarem expostas a uma maior variedade de estímulos.

\section{Compreensão dos conceitos}

Pessoas dotadas e talentosas são únicas e se constituem a partir de características genéticas, do ambiente a que são expostas e do grupo ao qual pertencem (GUENTHER, 2006b). Não fazem parte de um grupo homogêneo, sendo iguais aos demais, em relaçáo ao desenvolvimento esperado para cada faixa etária e estágio do desenvolvimento. Elas náo queimam etapas do desenvolvimento, mas tendem a passar por elas de forma mais rápida e, com isso, se destacam em relaçáo a seus pares de idade, sendo notadas como diferentes, pelos professores, pais e pessoas que as cercam. 
A pessoa talentosa possui uma capacidade natural, que vai além da média de seus pares, ou seja, ela só é talentosa se for dotada de capacidade. Em contrapartida, uma pessoa com capacidade natural pode nunca ter seu dote expresso em um talento devido à inexistência de estimulação do ambiente (GAGNÉ; GUENTHER, 2010).

Essa afirmação lança por terra a ideia errônea de que a pessoa mais capaz não precisa de atendimento diferenciado, pois já foi agraciada por Deus. Se ela não tiver um ambiente que propicie o desenvolvimento de seu potencial, seu dote nunca será expresso por meio de um talento, havendo um desperdício de sua capacidade inata.

A dotação "designa posse e uso de notável capacidade natural, em pelo menos um domínio da capacidade humana, entre pelo menos os $10 \%$ superiores no grupo comparável". O talento "designa alto desempenho e maestria em habilidades sistematicamente desenvolvidas, em algum campo de atividade humana, entre pelo menos os $10 \%$ superiores no grupo comparável exercendo atividade naquele campo" (GAGNÉ; GUENTHER, 2010).

Para Gagné existe uma participação importante do acaso nas realizaçôes humanas, pois ninguém controla a carga genética recebida, nem a família, ou mesmo o ambiente em que viverá.

Entre os $10 \%$ que se destacam em termos de capacidade natural, há uma divisão em 4 subgrupos: moderadamente, altamente, excepcionalmente e extremamente ou profundamente dotados e pessoas dotadas em um domínio não serấo necessariamente os mesmos dotados em outro (GAGNÉ; GUENTHER, 2010).

Para o desenvolvimento dos talentos e diferenciação dos termos dotação e talento Gagné criou o DMGT - Modelo Diferencial de Dotação e Talento. Nesse modelo as capacidades naturais ou aptidóes são a base para a constituição do talento.

É composto por três componentes básicos (dotaçáo, talento e o processo de desenvolvimento) e mais dois componentes adicionais (catalisadores intrapessoais e catalisadores ambientais).

A dotaçáo ou dote refere-se à capacidade natural e está agrupada em seis domínios, sendo quatro deles pertencentes ao sub-componente mental: domínio intelectual, domínio criativo, domínio social e domínio perceptual. Outros dois domínios correspondem à capacidade física: domínio muscular e domínio do controle motor.

Talento refere-se à realizaçáo e expressa um dote, pode ser chamado de capacidade e "é reconhecido na pessoa pela produçáo, atuação e desempenho, através do que ela consegue, alcança, visualiza e faz vir à tona durante a sua vida" (GUENTHER, 2006a, p. 52).

O desenvolvimento do talento se dá por meio da construçáo de um programa estruturado com metas, objetivos e período de tempo bem definidos com foco em um campo de atividade e que leve à excelência.

Os catalisadores intra-pessoais subdividem-se em aspectos físicos e psicológicos. As características pessoais do indivíduo, como temperamento e personalidade e os estilos adquiridos de comportamento, como motivação, autogestão, autonomia, manejo 
do tempo, iniciativa, concentração e hábito de trabalho podem tanto estimular quanto bloquear o desenvolvimento de talentos (GUENTHER, 2008, p. 35-42).

Já os catalisadores ambientais referem-se a influência do meio ao qual o indivíduo pertence como família, escola, comunidade e podem influenciar sobremaneira o desenvolvimento dos talentos (GUENTHER, 2008, p. 35-42).

O talento só é reconhecido pelos pares se for expresso em áreas valorizadas na cultura e na sociedade em que a pessoa vive. Um Pagé, por exemplo, só é reconhecido como alguém que detém um conhecimento elevado na cultura indígena. "Os talentos específicos que são valorizados dependem dos requisitos da sociedade para a sobrevivência e das crenças de sua populaçáo" (MUSSEN ET AL., 1995, p. 299).

Sendo assim, pessoas talentosas têm mais chances de alcançar sucesso na vida se tiverem destaque nessas áreas valorizadas em sua sociedade e cultura.

\section{caso de Anita Malfatti}

Nascida em 2 de dezembro de 1889, em Sáo Paulo, Anita Catarina Malfatti, filha do engenheiro imigrante italiano Samuel Malfatti e da pintora norte-americana de origem alemã Eleonora Elizabeth Krug, é considerada a pioneira da Arte Moderna no Brasil.

Com um defeito congênito no braço direito, aos três anos, submeteu-se a uma cirurgia, na Itália, no entanto, não houve recuperação total dos movimentos. Aos cinco anos, foi matriculada no Colégio São José, aprendendo a ler e escrever, mas sua habilidade com o desenho começava chamar a atenção. Teve o apoio da governanta da casa, Miss Browne, para desenvolver as habilidades com a mão esquerda. Mais tarde, usaria o pincel na mão esquerda e a paleta na mão direita, aplicando cores com traços vigorosos e movimentos livres.

Seu gosto pela pintura foi influenciado pelo tio, o engenheiro Jorge Krug, e por sua mãe, que dava aulas de pintura e idiomas, iniciando estudos mais aprofundados aos treze anos. Aos dezessete anos, Anita se forma e começa a dar aulas de pintura para ajudar em casa, no entanto, nutria o sonho de estudar em Paris.

Com o apoio financeiro do padrinho, Anita embarca para Berlim, em 1910, com as irmãs Shalders e se encanta com a vida cultural e a efervescência da cidade. Visitam museus, vão a concertos e Anita acompanha suas amigas ao Centro Musical, onde acaba conhecendo e sendo orientada, durante 6 meses, por Fritz Burger, um retratista que dominava a técnica expressionista ${ }^{1}$.

Em seguida, presta exames e ingressa na Academia Real de Belas Artes, mas, após um ano, percebe que a arte acadêmica náo a interessa e abandona os estudos.

Pouco tempo depois, encontra Lovis Coutinho e passa a ter aulas com ele. Lovis era conhecido por não ter paciência com os alunos, mas se rendeu ao talento daquela moça. Seu incentivo transformou-a em uma artista. 
Nesse período, aprendeu gravura em metal, suavizou os traçados e, cada vez mais, se interessava pela pintura expressionista, dedicando-se, em 1913, com Ernst Bichoff Klum, a aprender tal técnica.

Retornou ao Brasil em 1914, trazendo consigo a experiência e o sentimento expressionista, que a fizeram passar por problemas, afinal os parentes e amigos não suspeitavam que ela estivesse entregue à Arte Moderna. O Brasil valorizava e respeitava somente a arte acadêmica e isso fez com que todos estranhassem quando Anita pintou o irmão, Alexandre, com bruscas pinceladas, misturadas diretamente na tela e com um colorido particular.

Aos vinte e quatro anos, ela questiona o que leva a pintura a ser reconhecida como obra, sem imaginar que estava introduzindo uma nova arte no país, que chocaria as pessoas.

Nesse momento, desejava se aprimorar em Paris, e precisava de uma bolsa de estudos do Pensionato Artístico do Estado, e, então, realizou sua primeira Mostra, inaugurada em 23 de maio de 1914. Após a exposição, Nestor Rangel Pestana, crítico de arte, reconheceu o talento de Anita, mas, por conta da guerra, o governo suspendeu as bolsas de estudos.

Então, mais uma vez, Anita contou com o auxílio de seu padrinho, que financiou sua ida, em 1915, para Nova Iorque, que vivia um momento de expansão intelectual e artística, com a pretensão de que ela suavizasse sua pintura. Chegando lá, e por orientação da família, matriculou-se na escola Art Students League, passando a estudar gravura e pintura.

Interessada em retomar o vigor e o movimento que gostava de imprimir em seus trabalhos, matriculou-se no Independent Scholl of Art, onde conheceu o pintor e filósofo Homer Boss, que respeitava o ritmo e a expressão de cada aluno, orientando Anita a retomar seu estilo, o Expressionismo, distanciando-se completamente da arte esperada por seus familiares.

Em 1916, Anita retorna ao Brasil, trazendo consigo uma nova pintura, diferente daquela a que os brasileiros estavam acostumados a ver, decepcionando e escandalizando a todos com sua arte, que passou a ser nomeada como "coisas dantescas". Com isso, Anita se entristece, guarda suas obras e tenta recomeçar de um modo mais tradicional.

Para se manter, já que havia perdido o apoio do padrinho, que se decepcionara com ela, volta a lecionar e pintar sob encomenda. Com o nacionalismo em alta, decide pintar temas regionais, distanciando-se do Expressionismo e partindo para o Realismo.

Participa do Inquérito Nacional sobre o Saci, organizado por Monteiro Lobato, e sua obra fica isolada das outras por não ser nada Realista, causando admiraçáo, polêmica e atraindo curiosos, como Di Cavalcanti, que, logo em seguida, reúne alguns jornalistas para apreciar as "obras dantescas", que impressionam a todos. 
Em 13 de dezembro de 1917, com a esperança de que fosse compreendida, Anita Malfatti organiza sua 2a exposição. Todos os presentes ficaram surpresos e escandalizados com o que viram e em dúvida sobre a qualidade do seu trabalho, no entanto, começava a brotar na sociedade um desejo de mudança. Sua obra "A boba" foi duramente criticada por Monteiro Lobato e pela ala conservadora da elite cultural de São Paulo.

No dia 20 de dezembro do mesmo ano, Monteiro Lobato, que escrevia para o Jornal "O Estado de São Paulo", publica o artigo "A propósito da exposição Malfatti”, tecendo duras críticas à artista.

Oswald de Andrade a defende e enaltece sua coragem em expor algo inédito no país. Suas obras são reconhecidas e valorizadas por aqueles que passariam a defender o Modernismo.

Muitas obras foram devolvidas, outras quase destruídas e Anita mergulhou em profunda tristeza, isolando-se de todos e suprimindo sua inquietação e entusiasmo, pela segunda vez, e retomando, em 1919, os estudos acadêmicos.

Nessa época, ao frequentar o ateliê de Pedro Alexandrino, conhece Tarsila do Amaral, que também estranha sua obra, no início. Com uma nova forma de pintar, mais suave e menos violenta, a família e os críticos ficam mais satisfeitos e ela passa a receber mais encomendas.

Em 1929, tenta novamente ganhar uma bolsa de estudos e organiza outra exposição. Dessa vez, o governo reconhece seu talento, mas quem recebe a bolsa é Victor Brecheret.

Durante a exposição, ela conhece Mário de Andrade, que se tornaria seu grande incentivador e por quem se apaixonaria. Essa paixão durou até o fim de seus dias e fez com que ela o desenhasse de diversas formas. Uma dessas telas levou-os a brigarem e ficaram sem se entender, até que ele falecesse.

Anita passa então a frequentar os encontros com os Modernistas e em fevereiro de 1922, é inaugurada, no Teatro Municipal, a Semana de Arte Moderna, o evento cultural mais importante do século XX.

Em meio ao choque e ao espanto da sociedade, as obras de Anita se destacam. "Com o tempo, os intelectuais e o público em geral começaram a perceber que a nova arte trazia consigo um novo pensamento, um olhar diferente, uma expressão que precisava ser respeitada” (BRAGA-TORRES, 2002, p. 26).

Em 1923, no auge da vanguarda europeia, Anita ganha a tão sonhada bolsa e embarca para Paris, sem se despedir de Mário, que lhe envia um telegrama no navio.

Como era bolsista, precisava cumprir certas regras do governo, que exigia domínio da arte acadêmica e a execução de cópias de temas mitológicos e religiosos. Assim, Anita teve acesso ao Museu do Louvre, na França, e outros da Itália, para "copiar anjos, madonas e aprender a técnica da gravação a ouro e prata” (BRAGA-TORRES, 2002, p. 28). 
Em 1928, retornou ao Brasil, sendo recebida como uma verdadeira artista, consagrada por sua obra. Participou, a partir de 1930, de diversos eventos, fundou a Sociedade Pró-Arte Moderna, organizando a primeira exposição com trabalhos de alunos, montou um curso de História da Arte e fez diversas conferências.

Ainda em 1962, Anita comemorou o $40^{\circ}$ aniversário da Semana de Arte Moderna. No ano seguinte, foi homenageada na VI Bienal Internacional de São Paulo, com uma sala dedicada à sua obra.

Faleceu em 6 de novembro de 1964, aos 75 anos, mas "deixou vivos seus ideais, sua coragem e as amizades que, quando sinceras criam força para mudar o rumo da história" (BRAGA-TORRES, 2002, p. 32).

\section{Desenvolvimento}

Anita nasceu em uma família que prezava pela liberdade e cultivava o gosto pela arte. Aos cinco anos, apresentou as primeiras manifestaçóes de que era uma criança diferenciada aprendendo a ler e escrever com facilidade e demonstrando em seus traçados um dote a ser lapidado.

Teve sua dotação descoberta cedo, pela mãe, que também era pintora, e que passou a estimulá-la para que pudesse refinar sua capacidade natural. Essa estimulação da família perpassou sua formação escolar, pois, Anita, após a morte do pai, contou com o auxílio financeiro de seu padrinho, para que pudesse estudar nas melhores escolas e aprimorar seu potencial.

Caso a mãe de Anita nunca tivesse percebido que havia um potencial, um dote, talvez não lhe tivessem sido oferecidas as condiçóes ambientais para o desenvolvimento de sua capacidade, com isso, seu talento nunca seria expresso.

É nessa perspectiva que se faz necessário marcar o quanto o reconhecimento pela cultura influencia, sobremaneira, a vida dessas pessoas, na medida em que só há talento expresso se houver o desenvolvimento de uma capacidade natural.

Anita enfrentou diversos obstáculos, ao longo da vida, o primeiro deles, sua limitação física, superada à custa de muito investimento, da mãe e da babá. Outra barreira foi o fato de que, em sua época, a mulher não encontrava espaço na sociedade, sendo-lhe reservado apenas o papel de esposa e dona de casa. Além disso, ela trazia, ao Brasil, uma arte desconhecida e foi combatida por isso.

Sua vida foi marcada por idas e vindas à Europa e aos Estados Unidos, para estudar nas melhores escolas de arte, sendo orientada por grandes mestres a desenvolver sua capacidade natural, mas, em seu país, não encontrava receptividade em relação a suas obras.

No Brasil, de Anita Malfatti, a única pintura reconhecida era a acadêmica e ela trazia em suas pinceladas vigorosas a influência do Expressionismo, considerado como bizarro e desprovido de sentido artístico.

Essa não aceitação, o espanto e a repulsa em relação a suas obras a levaram a desistir de seus interesses, para tentar corresponder às expectativas. Ao longo de sua 
trajetória, o que se percebeu foi uma mudança de linguagem em sua pintura, abandonando o Expressionismo e se aproximando da pintura acadêmica.

O custeio de seus estudos, pela família, só se manteve na medida em que suas produçôes correspondessem ao que se entendia por arte, naquela época.

No artigo "A propósito da Exposição Malfatti”2, escrito por Monteiro Lobato, e publicado no jornal "O Estado de São Paulo", por ocasião da $1^{a}$ Mostra de Anita, ele afirma que:

[...] seduzida pelas teorias do que ela chama arte moderna, penetrou nos domínios dum impressionismo discutibilíssimo, e pôe todo o seu talento a serviço duma nova espécie de caricatura. [...] É extensão da caricatura a regióes onde não havia até agora penetrado. Caricatura da cor, caricatura da forma - caricatura que não visa, como a primitiva, ressaltar uma idéia cômica, mas sim desnortear, aparvalhar o espectador (LOBATO, 1917 apud ROCHA, 1981, p. 87).

A biografia de Anita Malfatti serve para refletir sobre como se dá o reconhecimento de uma pessoa dotada e talentosa e qual o peso da cultura nesse evento.

Segundo Alencar (1986), "é uma tarefa difícil ou mesmo impossível propor uma definição precisa e aceita universalmente a respeito" do fenômeno da dotação e do talento. A importância dada ao sujeito com potencial superior depende da cultura de cada sociedade. Pois, via de regra, um indivíduo só é reconhecido quando se destaca em áreas e atividades que são valorizadas.

No artigo de Monteiro Lobato, apesar de todo seu discurso ácido, ele não deixa de reconhecer que havia um talento:

Essa artista possui talento vigoroso, fora do comum. Poucas vezes, através de uma obra torcida para a má direção, se notam tantas e tão preciosas qualidades latentes. Percebe-se de qualquer daqueles quadrinhos como a sua autora é independente, como é original, como é inventiva, em que alto grau possui um sem-número de qualidades inatas e adquiridas das mais fecundas para construir uma sólida individualidade artística (LOBATO, 1917 apud ROCHA, 1981, p. 87)

No entanto, é fácil perceber que a aceitação só ocorre com a mudança de direção de suas produçôes se alinhando com a arte reconhecida naquele momento histórico.

Isso fica claro no encerramento do artigo, quando ele afirma que as críticas são no sentido de trazê-la para o caminho certo, a fim de que ela náo desperdice seus talentos. Diz, ainda, que seus apologistas pensam como ele, só não expressam sua opiniāo de forma clara, por gentileza à moça.

É sabido que, se a sociedade ignora a parcela talentosa da população, perde "líderes criativos nas ciências, nas artes, na política, possivelmente recebendo em seu lugar indivíduos frustrados e por vezes desistentes da escola, da comunidade, da atividade pública, enfim, da vida em si” (LANDAU, 2002, p. 27). 
$\mathrm{Na}$ época de Malfatti, segundo pesquisa realizada por Biasoli-Alves (2000), por meio da observação de idosos que passaram a infância entre os anos de $1890 \mathrm{e}$ 1930/40, a distinção entre a educação ofertada a meninos e meninas era clara. Alguns valores eram transmitidos indistintamente, para meninos e meninas, como respeito, obediência, honestidade e trabalho, mas outros eram ligados somente às meninas, como submissão, delicadeza no trato, prendas domésticas e habilidades manuais.

A educação era diferente e buscava marcar essa distinção e o comportamento mais valorizado para as meninas era a "obediência aos mais velhos e ao grupo familiar" (BIASOLI-ALVES, 2000, p. 235). À mulher não era permitido transgredir as regras ou buscar a liberdade. Havia uma preocupação com seu futuro, pois a moça precisava apresentar virtudes, que a tornassem desejável como esposa, para conseguir um bom casamento.

Essa questão fica bastante clara no artigo de Monteiro Lobato, quando ele diz:

Os homens têm o vezo de não tomar a sério as mulheres. Essa é a razão de lhes darem sempre amabilidades quando elas pedem opinião. [...] E tivéssemos na Sra. Malfatti apenas uma "moça que pinta”, como há centenas por aí, sem denunciar centelhas de talento, calar-nos-íamos, ou talvez lhe déssemos meia dúzia desses adjetivos "bombons" que a crítica açucarada tem sempre à mão em se tratando de moças (LOBATO, 1917 apud ROCHA, 1981, p. 88-89).

Ao final dos anos de 1929, face às pressóes impostas pela modernidade e à crise financeira, começa-se a reconhecer a possibilidade de permitir à mulher espaço no mundo do trabalho (BIASOLI-ALVES, 2000).

Essa questão de gênero permanece até os dias de hoje, e, muitas vezes, deixamos de reconhecer o talento nas meninas, por ainda estarmos impregnados por uma cultura de desvalorização da mulher construída historicamente.

Existem pesquisas que apontam não haver diferenças de gênero, em relação ao reconhecimento de uma capacidade superior (LANDAU, 2002), no entanto, as meninas não são encaminhadas aos programas de atendimento com tanta frequência. Isso pode ser explicado, pois "meninos são encorajados a pensar e agir de modo independente, a fazer descobertas no mundo circundante, a arriscar-se. Meninas crescem de forma mais protegida e as dificuldades são removidas do seu caminho" (SILVERMAN, 1986 apud LANDAU, 2002, p. 114).

Ainda hoje é possível notar como nossa cultura continua impregnada por questóes do passado e, à mulher, continua reservado o papel de máe e esposa, sendo difícil sua ascensão e reconhecimento profissional.

No entanto, muito se tem discutido, nos últimos anos, em relação às pessoas dotadas e talentosas e os debates convergem para a necessidade de reconhecimento das peculiaridades dessas pessoas e de oferta de condiçóes que lhe permitam o desenvolvimento e o refinamento de suas habilidades e competências. 
Esses espaços devem ser oferecidos pelas escolas e por recursos da comunidade e outros locais. É nessa perspectiva que devemos caminhar, pensando o ser humano em sua totalidade, sem desconsiderar que o cognitivo faz parte de um todo e não basta desenvolver os potenciais intelectuais, deixando de lado o emocional e o afetivo. $\mathrm{O}$ ser humano é único e não há como fragmentá-lo, é preciso criar condiçôes para que ele se desenvolva de forma equilibrada e possa sentir-se feliz e realizado.

Anita teve momentos de depressáo e de abandono do seu talento. Chegou a se questionar enquanto talentosa, pois se via sozinha em meio a tantos obstáculos e à falta de reconhecimento. $\mathrm{O}$ ser humano anseia por sentir-se pertencente a um grupo, sendo reconhecido e valorizado, e quando isso náo ocorre há um sentimento de marginalidade, que pode gerar frustração e tristeza. É muito comum nos depararmos com pessoas que abrem máo do seu talento ou o escondem, para pertencerem a um grupo social.

Nesse aspecto, o investimento na formação das crianças e jovens é fundamental para a constituição de sujeitos saudáveis, equilibrados e felizes.

\section{Conclusão}

A história mostra que as pessoas sempre são reconhecidas por sua produtividade, mas não podemos nos esquecer daquelas que não conseguiram encontrar seu lugar no mundo. Outras não tiveram chances de descobrir seus dotes e desenvolvê-los a fim de alcançarem sua excelência e acabam sendo marginalizadas. Muitos sofrem por náo conseguirem se descobrir enquanto seres potencialmente capazes de contribuir para o mundo em que vivem.

Deveríamos encontrar outra forma de "enxergar" esses talentos, para que todos tenham as chances de que necessitam para se tornarem pessoas afetiva, social e cognitivamente equilibradas, aceitas e respeitadas, por si e pelos outros.

O grande desafio de nossa sociedade, na atualidade, é reconhecer as diferenças e valorizá-las, oferecendo às pessoas dotadas e talentosas melhores condiçóes para expressar seu talento, de forma a sentirem-se inseridas na vida em sociedade, sendo produtivas e autorrealizadas.

Essa transformaçáo deve começar pela escola, que, segundo Ribeiro (2004), é um espaço privilegiado para a sustentação do amadurecimento, na medida em que provê ao ser humano um ambiente estável e seguro, e proporciona a aquisição de relaçáo de responsabilidade com o outro, capacidade de soluçáo de conflitos e administração de instintos e impulsos.

Cada criança tem uma possibilidade para crescer e nós temos que pensar a escola que temos e a que precisamos construir para atender, efetivamente, essa população (Ribeiro, 2004). É importante salientar que deve ser oferecido à criança um ambiente que lhe transmita a estabilidade necessária para que ela possa ter seus talentos potenciais revelados e utilizados (LANDAU, 2002, p. 30). 
Anita Malfatti é um exemplo daquilo que inúmeras pessoas enfrentam, corriqueiramente, por não corresponderem ao que é esperado e ao que é valorizado como habilidade, que leva ao sucesso e ao reconhecimento.

Este estudo mostra que precisamos lutar contra a "solidão do fundista" (LANDAU, 2002, p. 27), tão bem descrita por Érica Landau, pois o talentoso pode ser aquele que está sempre adiante dos demais no aspecto intelectual, mas emocionalmente permanece solitário e incompreendido.

\section{Referências}

ALENCAR, E. M. L. S. Psicologia e educaçáo do superdotado. São Paulo: EPU, 1986. 97 p.

ALMEIDA, M. A.; CAPELLINI, V. L. M. F. Alunos talentosos: possíveis superdotados não notados. Porto Alegre/RS, PUCRS, v. 55, n. 1, p. 45-64, jan/abr.2005.

ASHBerY, J. et al. Dicionário da Pintura Moderna. São Paulo: Hemus, 1981. 380 p.

BIASOLI-ALVES, Z. M. M. Continuidades e rupturas no papel da mulher brasileira no século XX. Psicologia: Teoria e Pesquisa, Brasília, v. 16 n. 3, p. 233-239, set./dez 2000.

BRAGA-TORRES, A. Mestres das Artes no Brasil - Anita Malfatti. São Paulo: Editora Moderna, 2002. 32 p. DELOU, C. M. C. Educação de aluno com altas habilidades/superdotação: legislação e políticas educacionais para a inclusão. In: FLEITH, D. (Org.) A construçáo de práticas educacionais para alunos com altas habilidades/superdotaçáo. Brasília/DF: Ministério da Educação, 2007, vol. 01, p. 25-40.

GAGNÉ, F; GUENTHER, Z. C. O DMGT 2.0 de Françoys Gagné: Construindo talentos a partir da dotação. Sobredotação, ANEIS, Portugal, n. 11, p. 7-23, 2010.

GUENTHER, Z. C. Capacidade e talento: Um programa para a Escola. São Paulo, EPU, 2006a. 116 p.

Desenvolver capacidades e talentos: Um conceito de inclusão. Petrópolis, RJ. Vozes, 2006b. 183 p.

. Educaçáo de bem-dotados: alguns conceitos básicos. Psicopedagogia, out. 2003, ano 1, n. 2, p. 30-38.

Referencial e bases teóricas. In: Coleçáo Debutante-CEDET 15 anos, vol. 1. Lavras, MG, 2008. 42 p.

LANDAU, E. A coragem de ser superdotado. 2a ed. São Paulo: Arte \& Ciência, 2002. 224 p.

MUSSEN, P. H. et al. Desenvolvimento e personalidade da crianças. $3^{a}$ ed. Sáo Paulo: Editora HARBRA Ltda., 1995. 641 p.

READ, H. O sentido da Arte: esboço da arte, principalmente da pintura e da escultura e as bases dos julgamentos estéticos. 6a ed. São Paulo: IBRASA, 1978. 166 p.

ROCHA, R. Literatura Comentada: Monteiro Lobato. São Paulo: Abril Educação, 1981. 107 p.

RIBEIRO, M. J. O ensinar e o aprender em Winnicott: a teoria do amadurecimento emocional e suas contribuiçóes à psicologia escolar. 2004. Tese (Doutorado em Psicologia Clínica). Pontifícia Universidade Católica de São Paulo, São Paulo, 2004.

VIRGOLIM, A. M. R. Desenvolvimento do autoconceito. In: FLEITH, D. (Org.) A construçáo de práticas educacionais para alunos com altas habilidades/superdotação. Brasília/DF: Ministério da Educação, 2007, v. 02 , p. $35-53$.

\section{Notas}

${ }^{1} \mathrm{O}$ Expressionismo é definido como "demonstração exterior de sentimentos interiores e indica uma das maneiras fundamentais de perceber e representar o mundo em torno" (READ, 1978, p. 136), e sua forma espontânea é expressa por meio da caricatura. Faz parte da Escola Moderna de Arte e teve como um de seus fundadores Vincent van Gogh (ASHBERY, 1981).

${ }^{2}$ Posteriormente, o artigo ficou conhecido pela expressão "Paranóia ou Mistificação", e custou a Monteiro Lobato uma série de atritos com os precursores da Semana de Arte Moderna de 1922. 


\section{Correspondência}

Denise Rocha Belfort Arantes - Avenida Orlando Ranieri, n. 0885, bloco 12, apto 03, Parque residencial das Camélias, CEP: 17047-902, Bauru, São Paulo, Brasil.

E-mail: drbarantes@gmail.com

Recebido em 21 de agosto de 2015

Aprovado em 25 de novembro de 2015 
